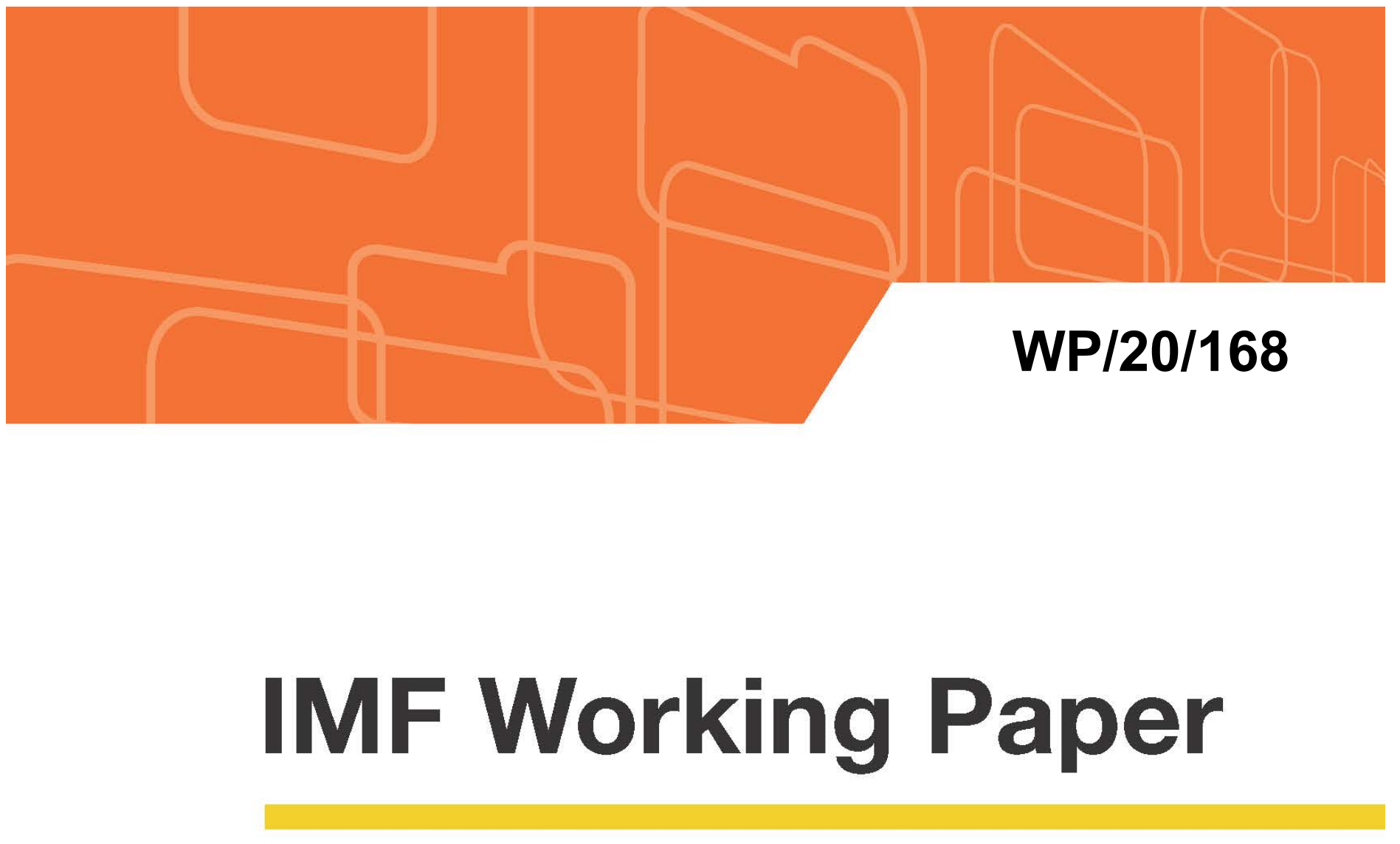

\title{
Mitigating Long-term Unemployment in Europe
}

by Hiroaki Miyamoto and Nujin Suphaphiphat

IMF Working Papers describe research in progress by the author(s) and are published to elicit comments and to encourage debate. The views expressed in IMF Working Papers are those of the author(s) and do not necessarily represent the views of the IMF, its Executive Board, or IMF management. 


\title{
IMF Working Paper
}

European Department

\section{Mitigating Long-term Unemployment in Europe Prepared by Hiroaki Miyamoto and Nujin Suphaphiphat ${ }^{1}$}

Authorized for distribution by Jaewoo Lee

August 2020

\section{IMF Working Papers describe research in progress by the author(s) and are published to elicit comments and to encourage debate. The views expressed in IMF Working Papers are those of the author(s) and do not necessarily represent the views of the IMF, its Executive Board, or IMF management.}

\begin{abstract}
While unemployment rates in Europe declined after the global financial crisis until 2018/19, the incidence of long-term unemployment, the share of people who have been unemployed for more than one year to the total unemployed, remained high. Moreover, the COVID-19 pandemic could aggravate the long-term unemployment. This paper explores factors associated with long-term unemployment in European countries, using panel of 25 European countries over the period 2000-18. We find that skill mismatches, labor market matching efficiency, and labor market policies are associated with the incidence of long-term unemployment. Among different types of active labor market policies, training and start-up incentives are found to be effective in reducing long-term unemployment.
\end{abstract}

JEL Classification Numbers: E24, J64, J68

Keywords: Long-term unemployment, labor market matching efficiency, and active labor market policy

Authors' E-Mail Addresses: hmiyamoto@tmu.ac.jp and nsuphaphiphat@imf.org.

\footnotetext{
${ }^{1}$ We are grateful for helpful comments and suggestions from Jorg W. Decressin, Jean-Jacques Hallaert, Jaewoo Lee, Yi Wu, and colleagues from Research department, European department, and the Bulgarian authorities.
} 
SECTION II: LONG-TERM UNEMPLOYMENT IN EUROPE 6

Long-term Unemployment Rate 6

Incidence of Long-term Unemployment __ 7

Impact of long-term unemployment___ 7

SECTION III: EMPIRICAL ANALYSIS ___ 8

Methodology and Data ___ 8

Main Findings _ 10

Robustness 13

SECTION IV: UNDERSTANDING THE POTENTIAL DRIVERS OF LTU 14

Labor market policy interventions: what, how, and which ones? 14

Skill mismatches: closing the digital skills gap 18

Labor market matching efficiency: the role of public employment services 22

SECTION V: CONCLUSIONS 23

REFERENCES 25

APPENDIX I: DATA 28 


\section{SECTION I: INTRODUCTION}

1. While the labor market situation improved alongside the economic recovery since 2014 through 2019, the incidence of long-term unemployment (LTU) remained high in the European Union. The unemployment rate in the European Union (EU) increased significantly during the global financial crisis (GFC), peaked in 2013, and then fell considerably to the level below the preGFC period at about 6 percent in 2019 . However, the incidence of LTU, the share of people who have been unemployed for more than one year to the total unemployed, remained higher than the pre-GFC level (average 2005-08).

During 2016-19, about 45 percent of the total unemployed are LTU, albeit down from 50 percent in 2014 .

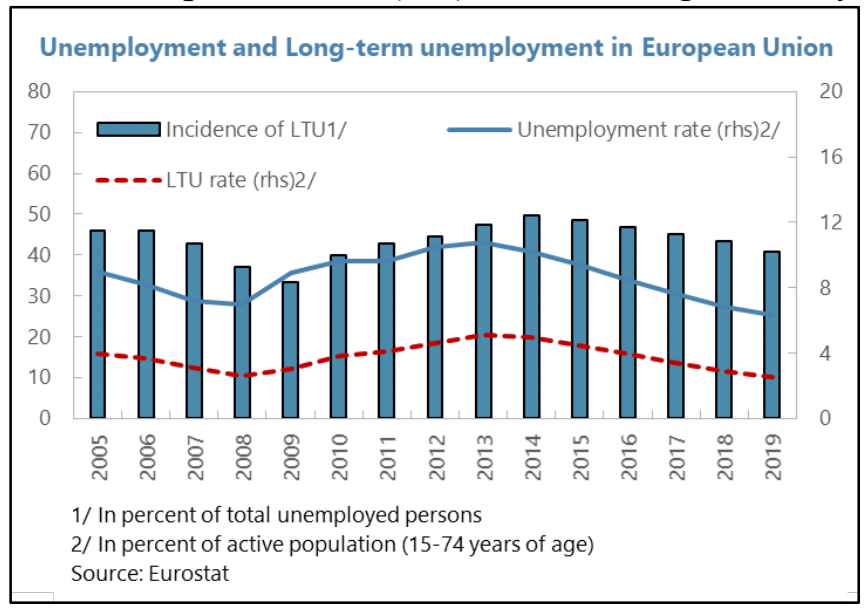

2. The COVID-19 crisis could further increase long-term unemployment. The pandemic and consequent lockdown have brought about a sharp contraction of activity and pushed up underemployment and unemployment, particular for low-skilled employees that cannot work from home. On average, the unemployment rate in Europe is projected to rise from 6.3 percent in 2019 to 9 percent in 2020 despite comprehensive support programs from the government (European Commission, 2020). Despite the gradual recovery that is expected to start in late 2020 and 2021, such a weak labor market and post-COVID reallocation would likely increase the pool of the long-term unemployed due to labor market hysteresis (Blanchard and Summers, 1986; Ball et al., 2014). Policies to reduce the long-term unemployed will contribute to limiting the scarring effect of the COVID-crisis on the labor market and overall economy.

3. LTU has an adverse impact on individuals and the whole economy. LTU causes significant mental and material stress for those affected through loss of income and social link with communities. It also has adverse consequences for the economy through deterioration of human capital from skill erosion and higher probability of exiting the labor market. Machin and Manning (1999) note that a high incidence of LTU means that unemployment is disproportionately concentrated on a small group of individuals and that it will be a potent cause of income inequality, given that a lack of work is the most important cause of poverty among working-age households in most European countries.

4. Using the panel data for 25 European countries over the period 2000-18, this paper finds that skill mismatches and labor market matching efficiency are associated with the incidence of LTU. When skills of the unemployed no longer meet labor demand, it contributes to protracted unemployment. The erosion of skills during unemployment would 
worsen the situation. In addition, the incidence of LTU is negatively associated with the labor market matching efficiency that we estimate.

\section{The estimation of labor market matching efficiency is another contribution of}

the paper. Most studies measure labor market matching efficiency through the shift of "the Beveridge curve," the inverse relationship between unemployment and vacancies. That is, an outward shift of the Beveridge curve indicates a decline in labor market matching efficiency. ${ }^{2}$ Nonetheless, a shift in the Beveridge curve could reflect temporary, cyclical, and demanddriven shocks, rather than structural changes in the labor market (i.e. matching efficiency). Our paper addresses the issue by estimating labor market matching efficiency based on a search-matching theory for $25 \mathrm{EU}$ countries and offers a cross-country perspective on the development of job market matching efficiency in Europe.

\section{Our analysis also finds that training and start-up incentives are negatively} associated with the incidence of LTU. These are consistent with the literature on the effects of active labor market policies (ALMPs) on employment, which shows that training and private sector employment programs are generally more effective in alleviating unemployment in the medium-to-long term, while direct job creation is less effective (Card et al., 2010, 2018). In addition, start-up incentives and measures aimed at vulnerable groups (including the LTU) are more effective than other ALMPs in reducing unemployment.

\section{Our results imply that a high incidence of LTU could be alleviated through ensuring adequate spending on effective ALMPs, addressing skill mismatches, and enhancing labor market matching efficiency. These policies would also facilitate the} transition to the post-COVID labor market, in which the use of digitalization and automation across sectors will be accelerated and the companies could increasingly depend on short-term contracts and freelance workers to ensure their flexibility (World Economic Forum, 2020 and Forbes, 2020).

- Spending on effective ALMPS. Although there are no one-size-fits-all policies, there is a case for higher spending on effective ALMP programs, particularly for countries facing high LTU while spending less on effective ALMPs than the EU average. Such increase could be achieved through rebalancing the ALMP spending toward effective programs, including training and private sector incentives.

- $\quad$ Addressing skill mismatches. Apart from upgrading skills through education and training programs, policy interventions should correctly identify skills for the current and future needs. One of the most important skills, which is and will be increasingly critical for the EU labor force, is digital skills. In particular, the Cedefop's European skills and jobs survey

\footnotetext{
${ }^{2}$ The theory posits that given other things constant, lower job matching efficiency — an outward shift in the Beveridge curveleads to higher unemployment rate at a given vacancy rate.
} 
(ESJS) indicates that digital skill gaps in Europe are still large on average. Policies to develop a digital competence would help improve skill matching for the region.

- Improving labor market matching efficiency. According to our estimates, labor market matching efficiency for the EU generally declined after the GFC. One of the key instruments to improve the job matching efficiency, particularly for the disadvantaged and the long-term unemployed, is to strengthen the role of public employment services (PES).

8. The remainder of the paper is organized as follows. Section II presents labor market developments over the 2000-18 period in European countries with a focus on LTU. Section III describes the empirical methodology. Section IV presents main findings. Section V discusses the potential drivers of the LTU, their developments in Europe, and policy implications. Finally, Section VI concludes.

\section{SECTION II: LONG-TERM UNEMPLOYMENT IN EUROPE}

\section{LTU is typically measured by two indicators: the LTU rate and incidence of}

LTU. The LTU rate measures a share of the long-term unemployed to the total labor force, while the incidence of LTU measures a share of the long-term unemployed to the total unemployed. This section documents recent trends of LTU using both indicators in Europe (Figure 1).

\section{Long-term Unemployment Rate}

10. LTU remained a key challenge in some European countries, especially for those that were hit the hardest during the GFC. As of 2018/19, the LTU rate was the highest in Greece, where almost one in five working age population were LTU. Along with Spain, the LTU rate in Greece increased about four folds after the GFC, compared to the pre-crisis period. Nonetheless, there were significant improvements in LTU rates in some countries, many of which were the new member states (NMS). ${ }^{3}$ For instance, the LTU rate in Czech Republic halved from 3.3 percent during 2005-08 to less than 1.5 percent in 2018.

\section{In some countries, youth LTU rates remained high historically and increased} significantly after the GFC. Countries with high LTU rates tend to have very high long-term youth-unemployment rates. These include Greece, Italy, Spain, Croatia, and Slovakia. Between pre- and post-GFC, the most significant increases in LTU rates among young people were seen in Greece (more than 15 percentage points), Italy and Spain (about 10 percentage points increases). Overall youth long-term unemployment rates declined significantly in Germany and in many NMS, particularly in Poland, Czech Republic, Hungary, and Slovakia.

\footnotetext{
${ }^{3}$ NMS includes Bulgaria, Croatia, Czech Republic, Estonia, Hungary, Latvia, Lithuania, Poland, Romania, Slovakia, and Slovenia.
} 


\section{Incidence of Long-term Unemployment}

12. Despite significant improvement in the LTU rate, the incidence of LTU remained elevated in the EU. After the GFC, the EU average of the incidence of LTU slightly increased to 46 percent, compared to 43 percent during 2005-08. Greece had the highest level of incidence of LTU after the crisis, where almost $3 / 4$ of the unemployed were long-term, followed by Slovakia, Italy, and Bulgaria. Generally, when the LTU rate improved, the incidence of LTU also declined. The exceptions include Bulgaria and Belgium, where LTU rates declined after the GFC but the incidence of LTU increased, suggesting that LTU could be attributed to structural factors.

13. The incidence of LTU varied across demographic groups. Across age groups, the incidence of LTU in the EU was the highest in people with 50 years of age and older: 60 percent of the unemployed in that cohort were out of job for more than 12 months. By gender, the incidence of LTU appeared to be similar for male and female. By education levels, the incidence of LTU was the highest in those with low skill levels. Depending on the structure of the labor force and the long-term unemployment risk, either the low-skilled or those with medium skill levels represented the largest group among the unemployed. The risk of falling into long-term unemployment among those with an intermediate skill level was still high in several EU countries, including Greece, Spain, Croatia, Portugal, Slovakia, and Ireland. ${ }^{4}$

\section{Impact of long-term unemployment}

14. Addressing LTU would alleviate poverty and social exclusion, and be beneficial for many EU countries, particularly those with demographic challenges. LTU has adverse consequences for individuals and the economy as the long-term unemployed tend to suffer from low social mobility and face higher risk of poverty. Even those who are reemployed tend to earn less than in their previous jobs and are demoted from their past careers (Mitchell et al., 2013). Getting jobs for the long-term unemployed would bolster income and alleviate poverty. For countries facing demographic challenges, integrating the long-term unemployed into the labor market (and also discouraged persons) would help alleviate the issue as they are a potential source of productive labor. LTU also has negative effects on youths' prospects and their risk of social exclusion. Existing studies show that experiencing a protracted unemployment not only strongly affects all dimensions of a young person's psychological well-being and quality of life, but also weakens their future employment outcomes as well as trust in institutions (Eurofound, 2017; Duell et al., 2016).

\footnotetext{
${ }^{4}$ Another interesting aspect is to assess factor contributing to the incidence of LTU at a regional level (Elhorst, 2003). Nonetheless, our study is bounded by data limitation, particularly on ALMP spending at a regional level.
} 


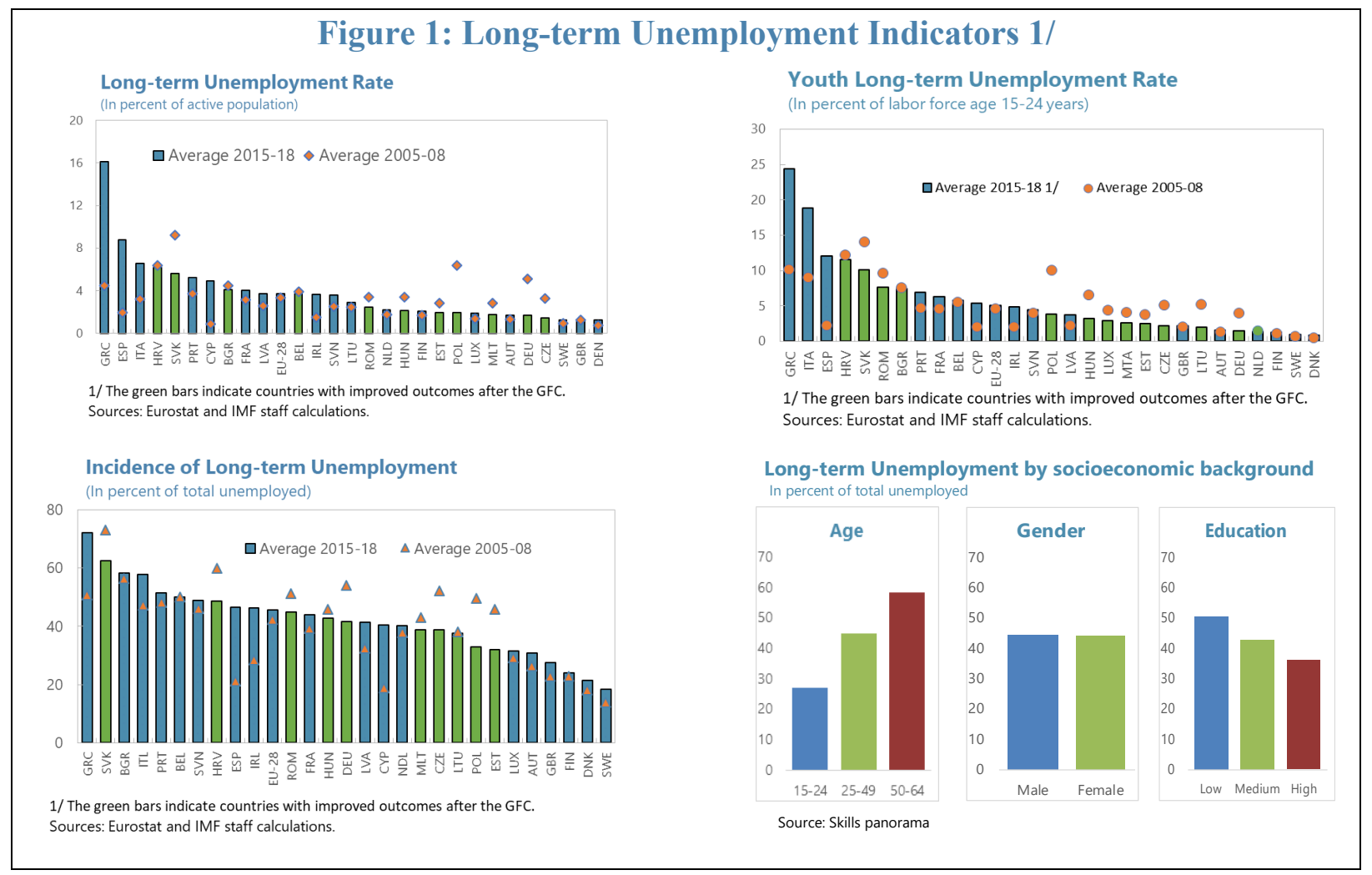

\section{SECTION III: EMPIRICAL ANALYSIS}

15. This section investigates factors associated with the high incidence of LTU in Europe. Our analysis proceeds in two steps. First, we regress the incidence of LTU on each explanatory variable separately. This allows us to get information about the co-movements between the incidence of LTU and the variable of interest. Second, we run full multivariate regressions to explore the drivers of LTU.

\section{Methodology and Data}

16. To explore the potential drivers of LTU, we consider the following panel regression model:

$$
L T U_{i t}=\gamma_{1} X_{i t}+\gamma_{2} Z_{i t}+\eta_{i}+v_{t}+\varepsilon_{i t}, \quad i=1, \ldots, N ; t=1, \ldots, T,
$$

Where $L T U_{i t}$ denotes the incidence of LTU of country $i$ in year $t, X_{i t}$ is a vector of macroeconomic variables, and $Z_{i t}$ is a vector of policy variables. We have fixed effects for country $\left(\eta_{i}\right)$ and time $\left(v_{t}\right)$ to account for unobserved country-specific heterogeneity and the global common factor, and $\varepsilon_{i t}$ is a random error term. 
17. Regressors comprise macroeconomic and labor market variables. We include lagged GDP growth, inflation rate, skill mismatches, and estimated labor market matching efficiency. Based on the Okun's law and the Philips' curve, economic growth and inflation rate are inversely associated with unemployment and, to some extent, LTU. Moreover, LTU could be a result of the unemployed having skills that do not match demand and low matching efficiency (Pissarides, 2000). As the incidence of LTU is known to be persistent, we also include the lagged incidence of LTU (one lag). For policy variables, our model includes both passive and active labor market policies as well as a tax wedge. Literature shows that certain types of ALMPs are effective in reducing LTU (Card et al., 2010, 2018; Kluve et al., 2019). Moreover, unemployment benefits and a tax wedge also play some roles in reducing LTU (Bassanini and Duval, 2006; OECD, 2006).

\section{We use annual data for 25 European countries over the period 2000-18 (see}

Appendix I). Data for all variables (including underlying data for estimated variables) come from the Eurostat database. Labor market policy variables include both expenditures on active and passive labor market policies. They are defined as public spending on labor market policies (LMP) per unemployed and expressed in percent of GDP per capita, which is often used in empirical research on unemployment (e.g. Arpaia et al., 2014). Skill mismatch is calculated as a sum square of the differences between the shares of population and employment by education attainment (see Section V). Matching efficiency is computed by using the matching function approach (see Section V and Appendix II). Table 1 presents descriptive statistics and pairwise correlations for the incidence of LTU and its potential drivers.

Table 1. Summary statistics

\begin{tabular}{|c|c|c|c|c|c|c|c|c|}
\hline & LTU & $\begin{array}{c}\text { Growth } \\
\text { rate }\end{array}$ & $\begin{array}{c}\text { Inflation } \\
\text { rate }\end{array}$ & $\begin{array}{c}\text { Skill } \\
\text { mismatch }\end{array}$ & $\begin{array}{l}\text { Matching } \\
\text { efficiency }\end{array}$ & NEET rate & Tax wedge & LMP \\
\hline Mean & 0.42 & 0.05 & 0.03 & 14.52 & 0.68 & 14.65 & 37.53 & 0.37 \\
\hline Std. Dev. & 0.13 & 0.07 & 0.03 & 8.08 & 0.53 & 5.46 & 7.36 & 0.29 \\
\hline Min & 0.09 & -0.30 & -0.02 & 0.77 & 0.16 & 4.10 & 11.90 & 0.03 \\
\hline Max & 0.76 & 0.35 & 0.46 & 43.13 & 4.61 & 32.50 & 51.40 & 2.13 \\
\hline \multicolumn{9}{|l|}{ Correlation Matrix } \\
\hline LTU & 1.00 & & & & & & & \\
\hline Growth rate (lagged) & -0.03 & 1.00 & & & & & & \\
\hline Inflation rate & -0.14 & 0.44 & 1.00 & & & & & \\
\hline Skill mismatch & 0.41 & 0.12 & 0.13 & 1.00 & & & & \\
\hline Matching efficiency & -0.37 & 0.02 & 0.08 & -0.24 & 1.00 & & & \\
\hline NEET rate & 0.66 & -0.17 & -0.08 & 0.47 & -0.01 & 1.00 & & \\
\hline Tax wedge & 0.01 & 0.03 & 0.17 & 0.18 & -0.16 & -0.08 & 1.00 & \\
\hline LMP & -0.51 & -0.10 & -0.13 & -0.26 & 0.24 & -0.49 & -0.05 & 1.00 \\
\hline
\end{tabular}

Source: Authors' calculations 
19. Table 1 shows that the correlations between the incidence of LTU and its potential drivers are of expected signs. The incidence of LTU is negatively correlated with the lagged GDP growth rate and the inflation rate as suggested by the Okun's law and the Phillips curve. A positive correlation (0.41) between the incidence of LTU and skill mismatch is as expected. In line with the prediction of the search and matching model (Pissarides, 2000), the incidence of LTU and labor market matching efficiency are negatively correlated with the correlation of -0.37 . Furthermore, the incidence of LTU is also positively correlated with youth not in employment, education, or training (NEET). Finally, there is a negative relationship between the incidence of LTU and expenditures in labor market policies.

\section{Main Findings}

\section{Simple Regressions}

20. The incidence of LTU is persistent and negatively associated with GDP growth (Table 2). The incidence of LTU is positively correlated with its own lag, indicating some degree of persistence in LTU. According to a European Commission's assessment using longitudinal EU-LFS data, the persistence of LTU was the highest in Bulgaria, Greece, Lithuania, and Slovakia (European Commission, 2016). Moreover, consistent with Okun's law, which shows a negative relationship between GDP growth and unemployment rate, we find that higher economic growth is associated with lower incidence of LTU. However, our result shows that inflation does not have a statistically significant association with the incidence of LTU.

21. Labor market characteristics and policy intervention are associated with the incidence of LTU in expected directions (Table 2). An increase in skill mismatches and a higher share of NEET are statistically associated with higher incidence of LTU, while a decline in labor market matching efficiency is associated with higher incidence of LTU, in line with predictions from the search and matching theory. The tax wedge is often considered to be one of the main determinants of long-term and/or structural unemployment, as a high tax wedge may discourage employers from creating new jobs (OECD, 2006; Gianella et al., 2009; Orlandi, 2012). However, we find that the variable is not statistically significant in our analysis. Finally, we find that a more generous labor market policy intervention (including both unemployment benefits and active labor market policies) is associated with lower incidence of LTU. ${ }^{5}$

22. Since existing studies find that different types of ALMPs have different impacts on LTU, we now disaggregate our analysis by types of ALMPs. ALMPs consist of training, employment incentives, supported employment and rehabilitation, direct job creation, and start-up incentives (see Section V for details). The results (Table 3 column 1-5) show that except for direct job creation, all ALMPs have significant impacts on LTU, in line with the literature (Card et al.,2018).

\footnotetext{
${ }^{5}$ We have a similar result by using the lagged labor market policies.
} 
Table 2: Simple Regressions

\begin{tabular}{|c|c|c|c|c|c|c|c|c|}
\hline \multicolumn{9}{|c|}{ Dependent Variable: Incidence of LTU } \\
\hline & 1 & 2 & 3 & & 4 & 5 & 6 & 7 \\
\hline Lag of LTU & $\begin{array}{l}0.813 * * * \\
0.031\end{array}$ & $\begin{array}{l}0.785 * * * \\
0.032\end{array}$ & $\begin{array}{r}0.740 \\
0.032\end{array}$ & $* * *$ & $\begin{array}{l}0.656 * * * \\
0.045\end{array}$ & $\begin{array}{l}0.722 \text { *** } \\
0.030\end{array}$ & $\begin{array}{c}0.802 \text { *** } \\
0.033\end{array}$ & $\begin{array}{l}0.763 \text { *** } \\
0.036\end{array}$ \\
\hline Lag of GDP growth & $\begin{array}{c}-0.245 * * * \\
0.039\end{array}$ & & $\begin{array}{r}-0.247 \\
0.039\end{array}$ & $* * *$ & $\begin{array}{c}-0.269 * * * \\
0.048\end{array}$ & $\begin{array}{c}-0.111 * * * \\
0.040\end{array}$ & $\begin{array}{c}-0.248 * * * \\
0.043\end{array}$ & $\begin{array}{l}-0.282 * * * \\
0.044\end{array}$ \\
\hline Inflation rate & & $\begin{array}{r}-0.041 \\
0.095\end{array}$ & & & & & & \\
\hline Skill mismatches & & & $\begin{array}{r}0.003 \\
0.001\end{array}$ & & & & & \\
\hline Matching efficiency & & & & & $\begin{array}{c}-0.079 * * * \\
0.014\end{array}$ & & & \\
\hline NEET & & & & & & $\begin{array}{l}0.009 * * * \\
0.001\end{array}$ & & \\
\hline TAX wedge & & & & & & & $\begin{array}{r}0.002 \\
0.001\end{array}$ & \\
\hline Labor market policies & & & & & & & & $\begin{array}{c}-0.119 * * * \\
0.029 \\
\end{array}$ \\
\hline $\mathrm{N}$ & 456 & 453 & 429 & & 256 & 439 & 362 & 368 \\
\hline
\end{tabular}

\section{Table 3. Multivariate Regressions with individual ALMPs}

Dependent Variable: Incidence of LTU

\begin{tabular}{|c|c|c|c|c|c|c|c|c|c|c|c|c|}
\hline & 1 & & 2 & & 3 & & 4 & & 5 & & 6 & \\
\hline \multirow[t]{2}{*}{ Lag of LTU } & 0.79 & *** & 0.78 & 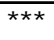 & 0.84 & *** & 0.81 & $* \star \star \star *$ & 0.82 & *** & 0.56 & 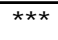 \\
\hline & 0.03 & & 0.03 & & 0.04 & & 0.04 & & 0.04 & & 0.07 & \\
\hline \multirow{2}{*}{ Lag of GDP growth } & -0.28 & 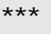 & -0.27 & $* \star \star$ & -0.26 & 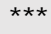 & -0.26 & 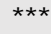 & -0.27 & *** & -0.16 & $\star \star * *$ \\
\hline & 0.04 & & 0.04 & & 0.05 & & 0.05 & & 0.05 & & 0.07 & \\
\hline \multicolumn{13}{|l|}{ ALMP } \\
\hline \multirow[t]{2}{*}{ Training } & -0.50 & *** & & & & & & & & & -0.67 & * \\
\hline & 0.15 & & & & & & & & & & 0.37 & \\
\hline \multirow{2}{*}{ Employment incentives } & & & -0.63 & $* \star *$ & & & & & & & -0.18 & \\
\hline & & & 0.16 & & & & & & & & 0.37 & \\
\hline \multirow{2}{*}{$\begin{array}{l}\text { Supported employment and } \\
\text { rehabilitation }\end{array}$} & & & & & -0.21 & * & & & & & 0.58 & \\
\hline & & & & & 0.12 & & & & & & 0.58 & \\
\hline \multirow[t]{2}{*}{ Direct job creation } & & & & & & & -0.10 & & & & -0.28 & \\
\hline & & & & & & & 0.09 & & & & 0.80 & \\
\hline \multirow[t]{2}{*}{ Start-up incentives } & & & & & & & & & -1.40 & ** & -3.41 & ** \\
\hline & & & & & & & & & 0.58 & & 1.65 & \\
\hline \multirow[t]{2}{*}{ Unemployment benefits } & & & & & & & & & & & 0.02 & \\
\hline & & & & & & & & & & & 0.13 & \\
\hline \multirow[t]{2}{*}{ Skill mismatches } & & & & & & & & & & & 0.003 & $* * *$ \\
\hline & & & & & & & & & & & 0.00 & \\
\hline \multirow[t]{2}{*}{ Matching efficiency } & & & & & & & & & & & -0.04 & ** \\
\hline & & & & & & & & & & & 0.02 & \\
\hline $\bar{N}$ & 372 & & 370 & & 290 & & 327 & & 339 & & 136 & \\
\hline
\end{tabular}

Notes: all models are estimated with a constant and time-effects. Robust standard errors are in italics. *, **, *** denote statistical significance at 10 percent, 5 percent, and 1 percent, respectively. All regressions include time and country fixed effects. 


\section{Full multivariate analysis with individual ALMPs}

23. Full multivariate regression shows skill mismatches, matching efficiency, and some types of labor market policies play an important role in explaining the incidence of LTU. The results (Table 3, column 6) show lag of LTU, lag of GDP growth, skill mismatches, and matching efficiency are statistically significant and have the expected signs. Moreover, among ALMPs, training and start-up incentives appear significant at explaining the incidence of LTU. Finally, although existing studies find higher unemployment benefits could lead to higher incidence of LTU, we find that the impact is not statistically significant in the full multivariate regression.

24. Our findings on the effects of ALMPs are line with the literature. Training programs and private sector incentives have been found to be effective at addressing LTU. Using meta-analysis, Card et al. (2018) find that long-term unemployed persons benefit more from ALMPs than other unemployed persons, particularly if there is emphasis on improving their human capital. Training measures tend to show positive medium- and long-run results (Card et al. 2010, 2018) but it is important to ensure that trained skills and competences serve the labor market demand (European Employment Observatory, 2012). Various studies (Rodriguez-Planas, 2010 and Escudero, 2018) show that start-up incentives are found to be effective in reducing unemployment and increasing employment in advanced economies, particularly for vulnerable and low-skilled people who face limited options in the labor market. Based on Caliendo and Künn (2011), start-up incentives are associated with a "double dividend" when subsidized firms create more jobs in the future. Generally, direct job creation in the public sector is found to be the least effective measure.

25. The literature has found that the design of the ALMPs is also important in determining the LMP effectiveness. Levy et al. (2019) find that program length, monetary incentives, individualized follow up and activity targeting are important in determining the effectiveness of the interventions. Similarly, Meager and Evans (1998) show that smaller scale and well-targeted programs to jobseekers' potential and employers' need are more effective than larger schemes. Duell (2012) find that early identification and intervention are important for increasing the effectiveness of ALMPs. Focusing on youth unemployment, Caliendo and Schmidl (2016) find a positive impact of job search assistance on employment but more mixed effects for training and wage subsidies. Nonetheless, Duell (2012) argue that pre-vocational measures such as vocational guidance and individualized counseling can improve effectiveness of integrating unemployed youth into the labor market. Finally, focusing on European active labor market policies including job search assistance, Kluve (2019) find that private sector incentive schemes, including start-up incentives and wage subsidies, and job search assistance programs "services and sanction" are effective.

26. Labor market matching efficiency, an ability to match the unemployed with vacancies, is also important for employability of the long-term unemployed. Many studies (Jackman et al., 1990; Franz, 1987; Johansen, 2004; Arpaia and Turrini, 2014; and 
Bova et al., 2016) found a negative relationship between the incidence of LTU and labor market matching efficiency. For example, Arpaia and Turrini (2014) found that high incidence of LTU has been associated with declining matching efficiency in Europe after the GFC. The quantitative analysis of search and matching models also shows that lower labor market matching efficiency accounts for higher incidence of LTU in the United States after the GFC (Kroft et al., 2016 and Hall and Schulhofer-Wohl, 2018).

\section{Robustness}

27. The main results are broadly robust. A significant degree of persistence in LTU implies that our estimators could be biased as the lagged dependent variable is correlated with the error term. To account for dynamic effects and address the endogeneity problem, we also perform dynamic panel data estimation as in Arellano and Bond (1991). The results are shown in Table 4 column (2). Similar to the fixed-effect estimation, the incidence of LTU is associated with skill mismatches, matching efficiencies, and some types of ALMPs. For robustness check, we also perform an OLS estimation on the pooled data (Table 4 column (3)). The results are similar to those of the benchmark and dynamic panel data estimation, although training is not statistically significant.

\section{The incidence of LTU appears to be more sensitive to economic growth,} matching efficiency and ALMPs in the NMS. We now apply the fixed-effect panel data estimation but limit the sample to the NMS. Table 4 column (4) shows that while the qualitative results remain broadly unchanged, the size of coefficients on of economic growth, matching efficiency, and ALMPs becomes larger for the NMS.

\section{Employment protection is not found to be associated with the incidence of LTU.} The role of employment protection legislation (EPL) on unemployment has been discussed in the literature. Its impact on long-term unemployment remains mixed in empirical studies. For example, OECD (2004) finds that strict employment protection increases the incidence of LTU, while Heckman and Pages-Serra (2000) show that EPL has no effect on long-term unemployment. By using the indicator of EPL developed by OECD, we find that EPL does not have statistically significant impact on the incidence of LTU. 
Table 4. Robustness Check

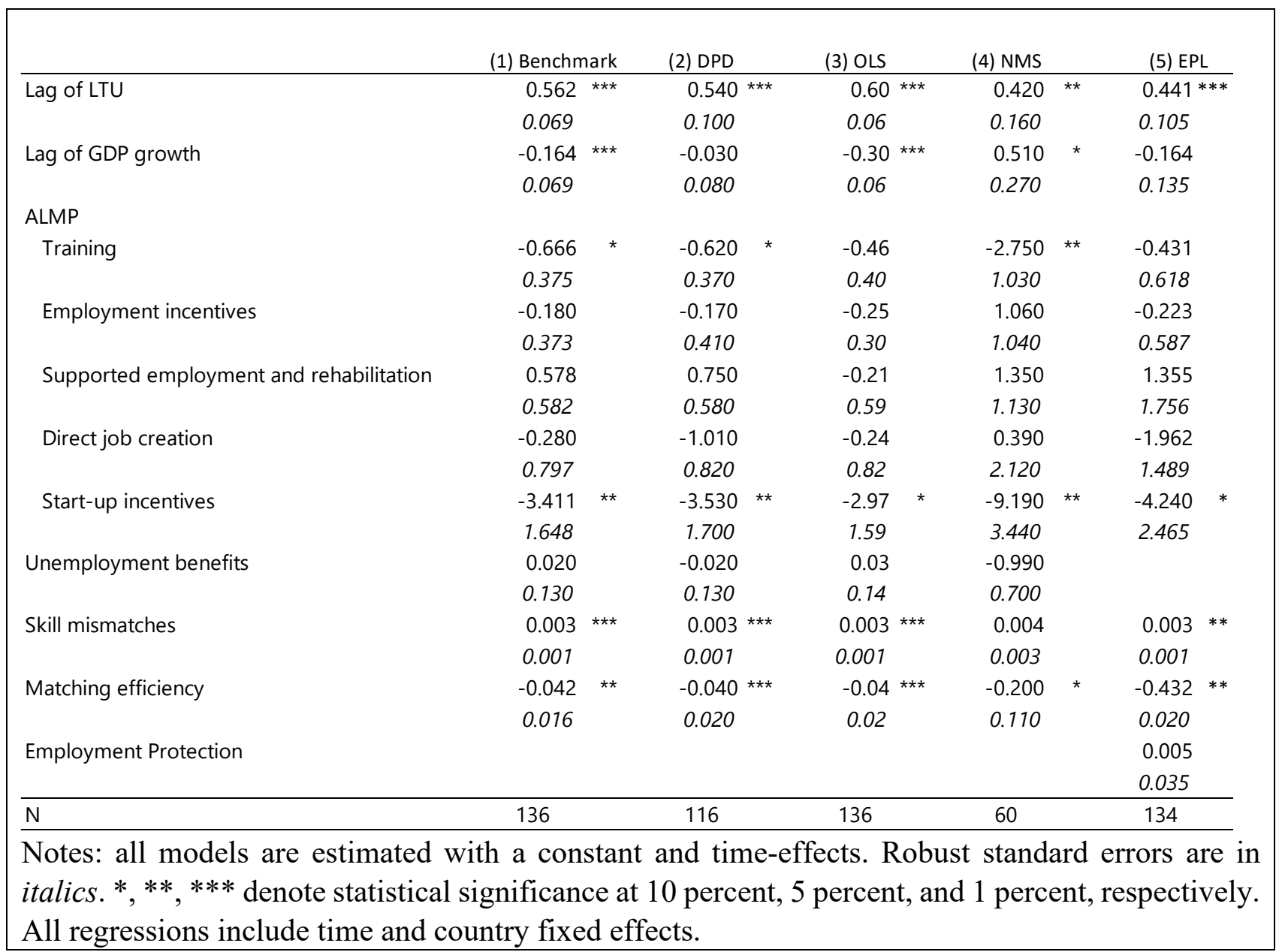

\section{SECTION IV: UNDERSTANDING THE POTENTIAL DRIVERS OF LTU}

30. This section focuses on three areas for potential policy intervention, which have been found significant in explaining the incidence of LTU in the EU countries. Our analysis shows that labor market policy intervention, skill mismatches, and matching efficiency are associated with the incidence of LTU. These variables are discussed in detail, including by presenting their developments and trends in the EU and suggesting policy implications drawn from various case studies.

\section{Labor market policy interventions: what, how, and which ones?}

31. Labor market policy interventions cover labor market services, passive, and active labor market policies. The Eurostat database breaks down labor market policies intervention into three main categories: (i) labor market services; (ii) passive labor market 
policies (PLMPs); and (iii) active labor market policies (ALMPs). Labor market services cover all services of the PES and any other publicly funded services for jobseekers. It generally includes "services and sanctions" and aims at enhancing job search efficiency (see labor market matching efficiency section). Second, PLMPs cover financial supports that aim to compensate jobseekers for loss of income during unemployment. They include unemployment benefits and incomes that facilitate early retirement. Finally, ALMPs cover policies that activate jobseekers to find employment. They comprise training, employment incentives, start-up incentives, supported employment and rehabilitation, and direct job creation (see Box I).

\section{Box I. Categories of Active Labor Market Policies}

Literature often categorizes active labor market policies into four main categories.

- Training programs aim to improve the quality of human capital by improving skills, productivity, and consequently employability. They include classroom training and apprenticeship. They cover a broad range of knowledge acquisition, including general education (such as language courses and basic computer courses) and/or specific vocational skills (e.g. advanced computer courses and technical and manufactural skills).

- Private sector incentive programs comprise employment incentives and start-up incentives. Employment incentives are provided with a view to encouraging employers to hire new workers or to maintaining jobs that would otherwise be eliminated. These incentives include wage subsidies to employers or financial incentives to workers. They frequently target long-term unemployed and more disadvantaged individuals. Start-up incentives aim to provide subsidies to jobseekers who want to start their own business and become self-employed. They include grants and sometimes advisory support for a fixed period.

- Supported employment and rehabilitation target disabled persons and those temporarily incapacitated after an accident or illness. They include measures that aim to promote the labor market integration of persons with reduced working capacity through sheltered or supported employment or through rehabilitation.

- Finally, direct employment programs focus on the direct job creation in the public or non-traded sectors. These measures are typically targeted at the most disadvantaged individuals.

Source: EUROSTAT, 2013, “Labor Market Policy Statistics Methodology 2013,” Eurostat Manuals and Guidelines. 


\section{The levels and types of spending in labor market policy intervention varied} considerably across Europe. These reflected diverse labor market characteristics, challenges, and government's priorities across countries. In 2017, the average LMP spending for the whole EU was at 1.3 percent of GDP but differed significantly across countries. In general, LMP spending in the advanced economies was twice as large as those in the NMS. By country, spending on LMP interventions ranged from just 0.1 percent of GDP in Romania to 3 percent of GDP in Denmark. In many countries, spending on LMP interventions peaked during the GFC and continued to decline to the levels slightly below the pre-crisis level. These countries included Denmark, Germany, Ireland, France, the Netherlands, Portugal, Romania, Sweden, and Finland.

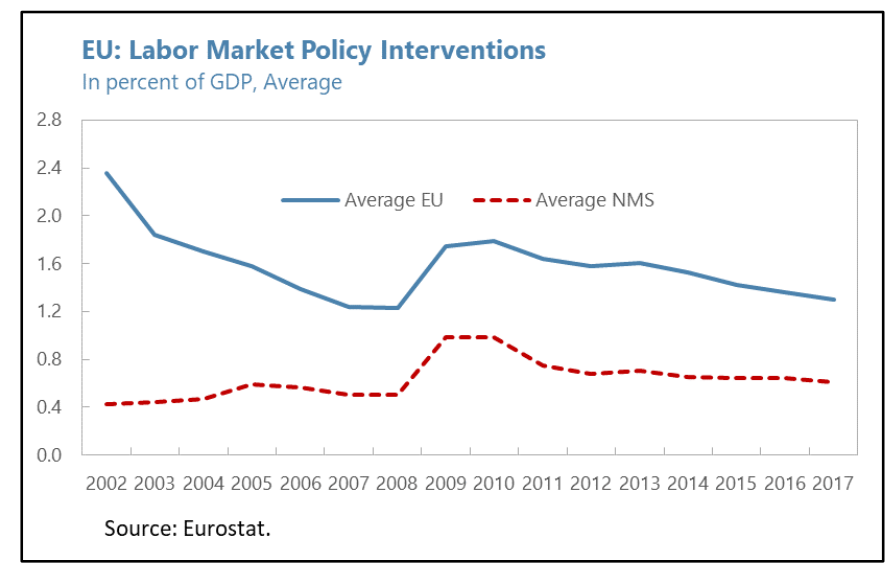

\section{Most countries allocated the largest share of LMP resources on PLMPs,} followed by ALMPs and PES, respectively. In 2017, Cyprus and Bulgaria allocated more than three-quarters of its LMP resources to PLMPs, in contrast with Hungary and Malta, where the shares of spending on PLMPs were about 20 and 15 percent of total labor market expenditure, respectively. For the EU average, about half of the LMP interventions spending was allocated to PLMPs (mostly in unemployment benefits), and one-third was spent on ALMPs. Some countries; however, put spending priorities on ALMPs. They included Czech Republic, Denmark, Croatia, Lithuania, Luxembourg, Hungary, and Poland. Malta was the only country among the EU that spent the

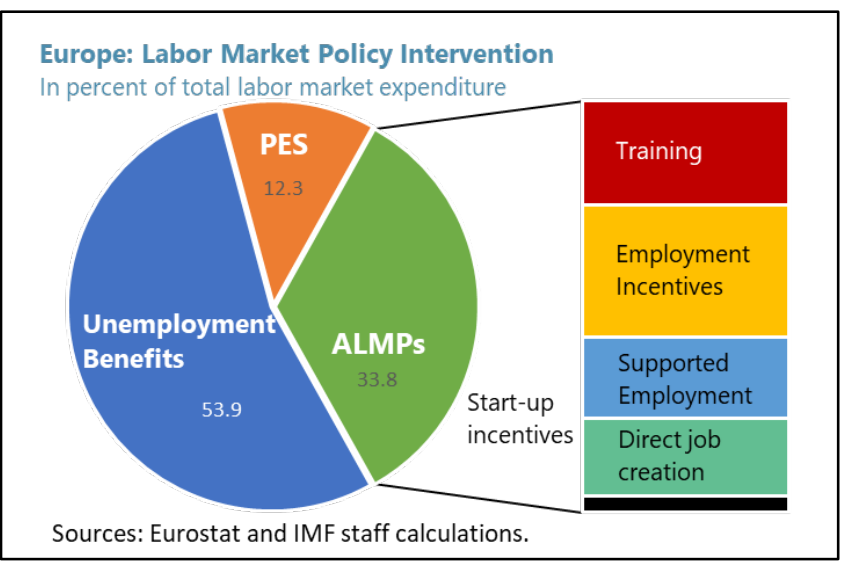
largest share of LMP on labor market services (PES). 
34. Across different types of ALMPs, most countries allocated resources to employment incentives, followed by training programs. On average, EU countries spent one-third of ALMPs on employment incentives in 2017, followed by training (about 30 percent), rehabilitation, and direct job creation, respectively. Start-up incentives generally accounted for a very small share in most countries (less than 5 percent), with exceptions for Spain, Poland, Sweden, and Croatia. There were significant country-level variations of

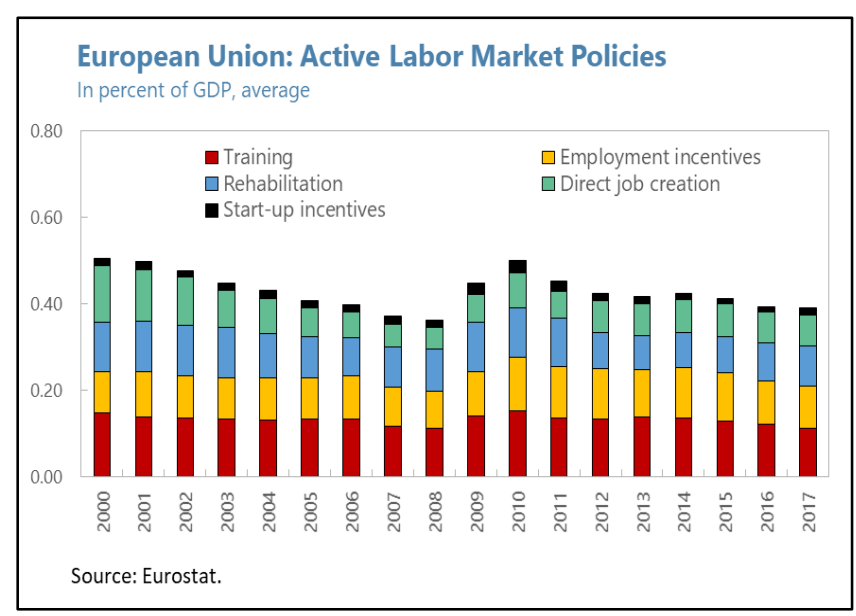
ALMP spending. While Austria, Germany, France, Croatia, Latvia, Portugal, and Finland prioritized their spending on the training programs, Bulgaria, Greece, Hungary, and Slovenia spent the largest share of their ALMP budgets on direct job creation.

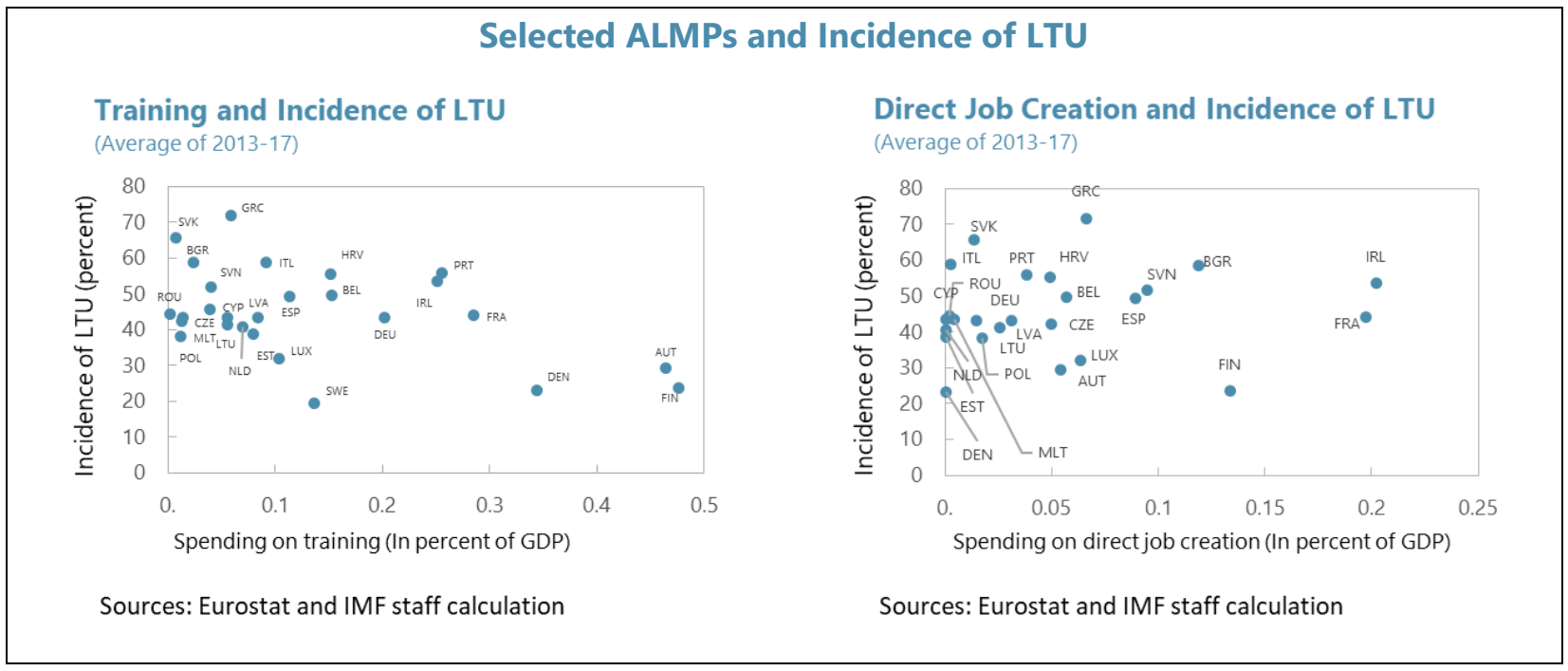

35. Policy implications: Existing literature, successful country experiences and our findings point to the following implications for designing ALMPs.

- Ensure adequate spending on effective ALMPs. In many countries with high LTU rates and incidence, spending on effective ALMPs could be increased while safeguarding efficiency. For example, in Bulgaria, spending on overall ALMPs was among the lowest in the EU, while the incidence of LTU was among the highest. Moreover, within the ALMPs, direct job creation received the largest allocation of resources. In this case, there is room to both increase the overall envelope of ALMP spending and shift spending away from direct job creation toward training programs and start-up incentives. 
Apply coherent and comprehensive approach. ALMPs should support various groups of LTU, including the vulnerable groups and those discouraged from work (inactive population). In general, combining different types of ALMPs, including training, counselling, and subsidies, appears to be more effective. For countries with high LTU rates, ALMPs should be widespread with additional measures for disadvantaged group, while in countries with low LTU rates, more tailored programs to disadvantaged groups would be more effective.

\section{Skill mismatches: closing the digital skills gap}

\section{Skill mismatches are defined as imbalances between skills demanded for labor} and skills available in labor supply. Ideally, the proper way to measure skill mismatch would require data on vacancies and unemployment separately for different skill levels, proxied by education. The higher is the discrepancy between vacancies and unemployment within a particular skill compared with that prevailing throughout the whole economy, the higher the associated degree of mismatch. As vacancies by education level are not available, we follow Estevao and Tsounta (2011) and construct a mismatch indicator as differences between employment and working-age population by education groups.

\section{The degree of skill mismatches} varied greatly across the $E U$ and across time. Skill mismatches appeared to be high in Belgium, Ireland, and Bulgaria, while they were low in the Netherlands, Portugal, and United Kingdom. Relative to pre-GFC, about half of the EU member states experienced an improvement in skill matching. The largest improvements occurred in many NMS. In contrast, skill mismatches deteriorated after the GFC in many advanced countries, including Ireland, Greece, Spain and Portugal.

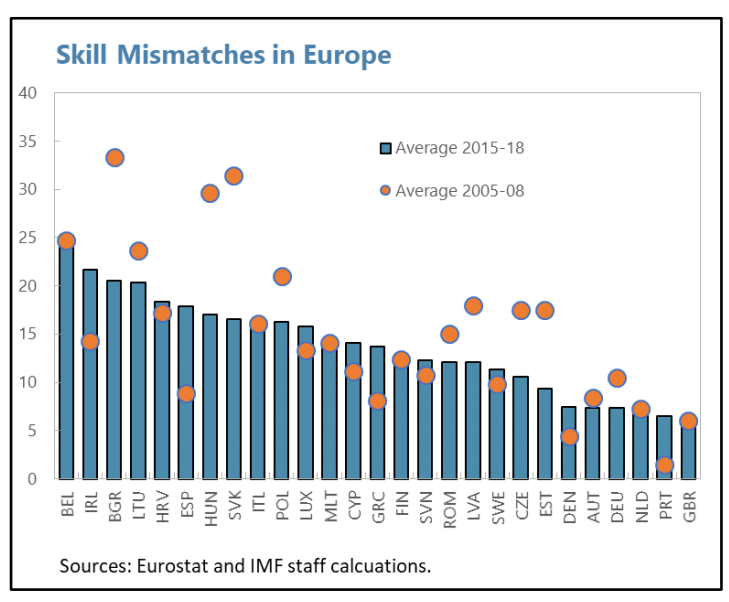

38. Digital skills are a pre-requisite for the current and future of work (Figure 2). Changes in skill demand and supply have resulted in difficulty for firms to find employees with the right skills (Cedefop, 2018). In light of a growing digitalized economy, the skills that will be increasingly in high demand include digital skills. Based on Cedefop's skills online vacancy analysis tool, almost half of vacancies were related to Information and Communication Technologies (ICT), healthcare, science, and business and retail sectors and they expected to increase in the future (Cedefop, 2018). Many of these vacancies require some knowledge of digital skills. According to the ESJS in 2014, more than 85 percent of the EU employers required at least basic ICT skills to perform the job. Going forward, future structural transformation of the EU labor markets will be accompanied by a high demand for digital skills. The experience of the COVID-19 lockdown will further increase the premium of digital skills. 
39. Most EU countries experienced digital skill gaps. Despite the growing importance of digital skills in the EU labor market, digital skill gaps - measured by the difference between percent of employees that need at least basic level of ICT skills in order to work and percent of individuals who have at least basic and overall digital skills - remained high in the EU. All countries except the Netherlands experienced skill gaps of at least 15 percent, where digital skill gaps in Bulgaria, Croatia, and Italy were as high as 50 percent.
Digital Skills Gaps, European Union 1/ In percent

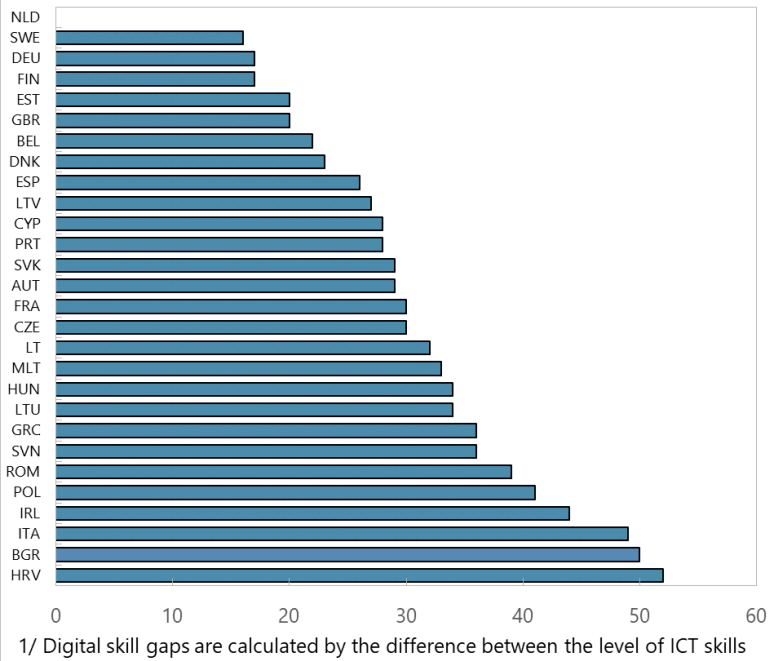

1/ Digital skill gaps are calculated by the difference between the level of ICT skills needed to do the job and percent of individuals who have at least basic and overall digital skills.

Sources: Cedefop's European Skills and Jobs Survey, 2014; Eurostat; and staff calculation. 
Figure 2: European Online Job Vacancies by Occupation and Skills

\section{Online Job Vacancies by Occupation 1/}

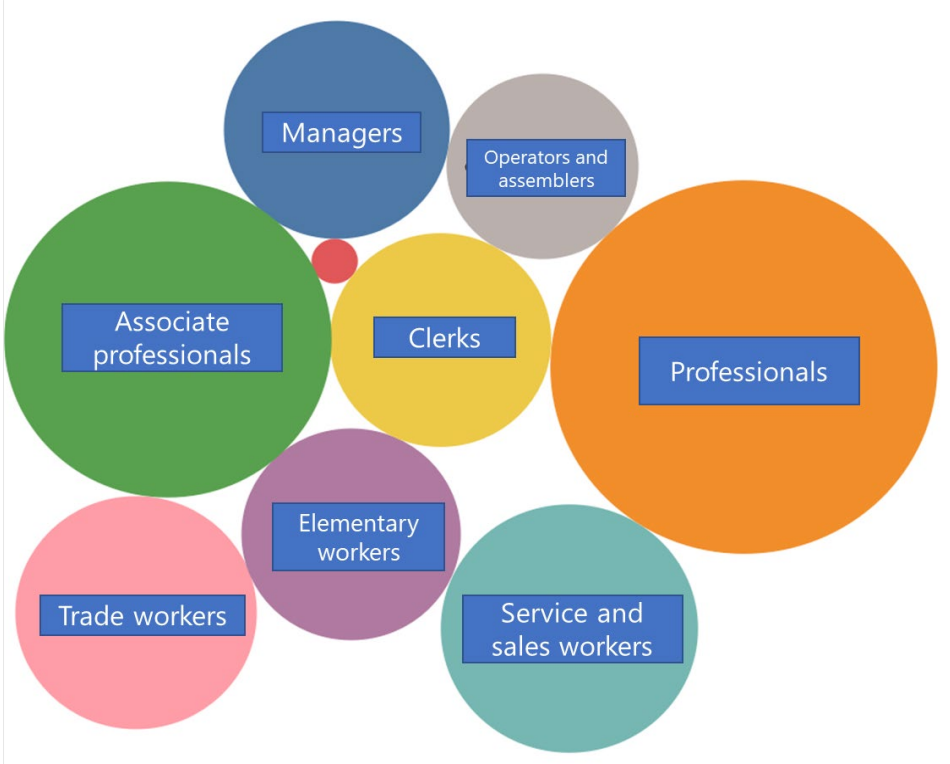

Most Requested Skills 2/

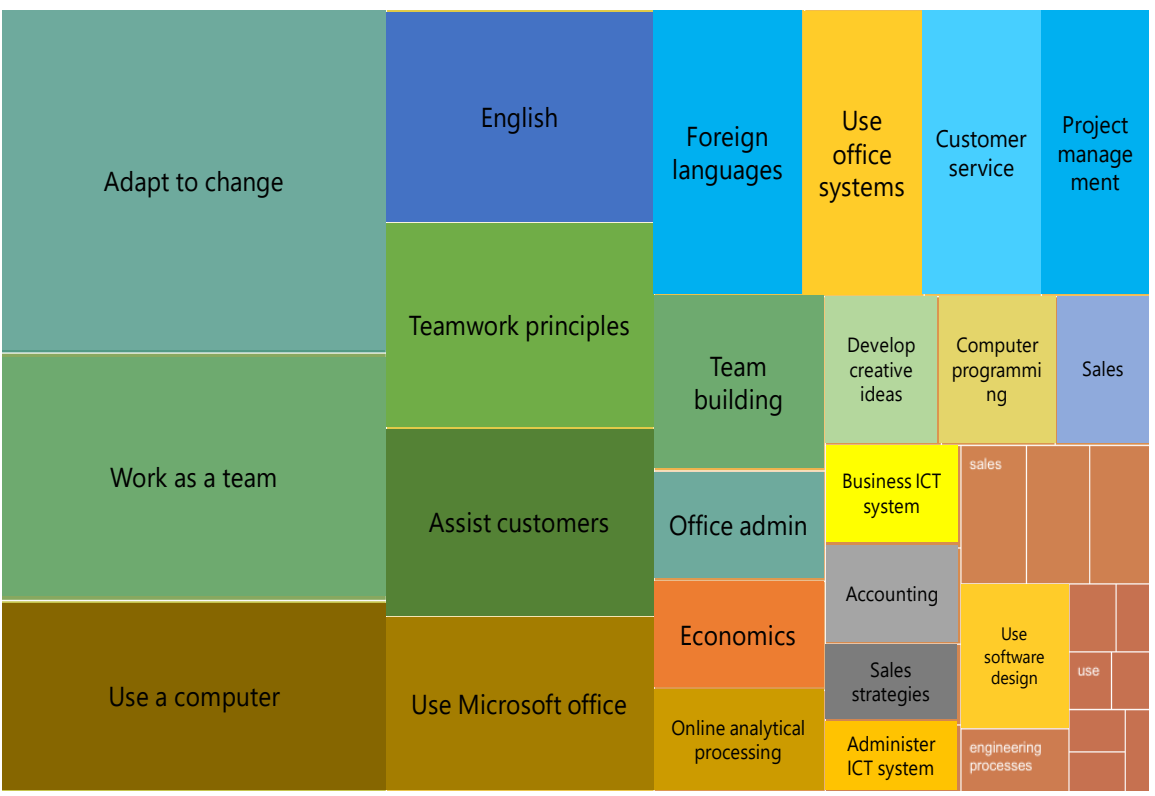

$1 /$ The relative sizes of the bubbles indicate relative numbers of online job vacancies.

2/ The relative sizes of squares indicate frequencies of skills requested in the online job vacancies. Source: Cedefop's Skills Online Vacancy Analysis Tool for Europe. 
40. Policy implications: Based on the experiences of the world's best performers in the area of digital skills, digital literacy can be strengthened through policies aimed at creating a conducive environment for the development of digital skills, and sectoral policies focusing on education and training.

- Create a digital-friendly economy by investing in technological infrastructure and promoting digitalization of businesses. High quality and extensive access to technological infrastructure such as telecommunication networks and access to internet can deepen the penetration of technology. Based on the Digital Economy and Society Index (DESI), Denmark, Finland, Luxembourg, the Netherlands, and Sweden have the most advanced digital connectivity, while Greece, Croatia, and Lithuania still have room for improvement, particularly on the coverage and take-up of the ultrafast broadband. Furthermore, promoting digitalization of businesses could foster development of digital skills, as growing uses of technology in businesses lead to higher demand for individuals with digital knowledge and result in internal training programs (UNESCO, 2018).

- Integrate technology into education and training.

$>$ Education system: The United Kingdom introduced programming lessons for children from age five and above to provide the students with a solid foundation for digital technology. Sweden integrated digital education into compulsory subjects such as Biology and Physics. Denmark integrated the use of ICT into student's examination, while Norway monitored and took stock of students' digital skills through a national digital skills evaluation test. Recognizing the importance of teachers, many EU countries and Hong Kong SAR developed an ICT training framework for teachers that allow them to upgrade their teaching methods. Finally, Singapore developed the ICT Master Plans for Education, including: i) equipping schools with warranted infrastructure; ii) training teachers to use technology and incorporate the knowledge into teaching methods; and iii) incorporating digital technology into curricula at all levels of education.

Adult training: In addition to boosting digital competency for students, upgrading adults' digital skills and promoting digital inclusion are equally important. Denmark has prioritized training in digital skills for employees in their labor market policy. Luxembourg offered one-on-one and group training sessions at affordable prices to low-income individuals and elderly. Sweden, New Zealand, and Singapore's governments cooperated closely with industries and businesses to identify present and future needs in digital skills and develop policies to promote training in required digital competencies. 


\section{Labor market matching efficiency: the role of public employment services}

\section{Labor market matching efficiency in EU generally declined after the GFC and improved slightly in recent years. Most EU countries experienced} declines in their matching efficiency immediately after the financial crisis (Figure A1). However, the recovery process in the post-crisis period differed across countries. For example, after deteriorating during the GFC, the matching efficiency improved to the pre-crisis level in the Czech Republic and Estonia. On the other hand, the matching efficiency in Bulgaria, Greece, Ireland, Lithuania, Romania, the United Kingdom, Spain, and Slovenia continued to decline.

\section{Strengthening the role of public employment services could enhance matching efficiency.}

Improving labor market matching efficiency requires policies beyond those aimed at stimulating aggregate demand, since it relates to structural factors, including institutional inefficiencies, that dissuade job seekers from accepting a job

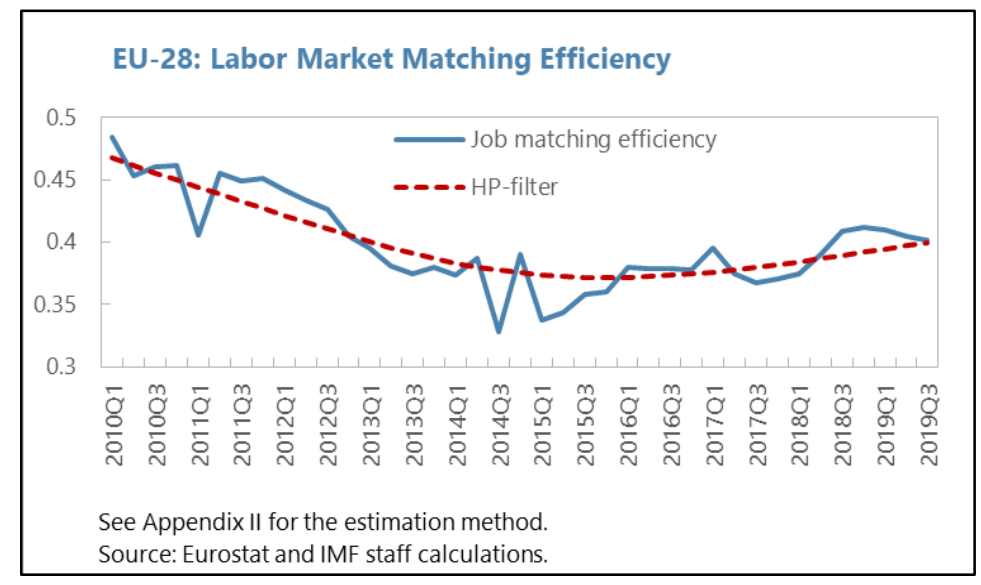

(Bova et al., 2016). PES play an important role in contributing to a well-functioning labor market, as they facilitate the process of matching the jobseekers and employers. Based on the EU's peer-to-peer review and G20 case studies, successful programs offered by PES that bring about sustainable employment for the LTU include the following factors.

- $\quad$ Targeted and personalized programs that combine several interventions. Initial profiling is an effective tool to categorize jobseekers prior to designing other interventions. Germany has developed a comprehensive skills assessment profiling tool, so called "Kodiak," and linked the profiles to regional labor market vacancies. It consists of self-assessment questionnaire, aptitude test, interview to assess achievement motivation, assessment of social and communication skills required in selected occupations, and technical standards for the analysis of personal skills. Denmark's approaches for interventions depend on matching groups categorized by the Employability Profiling Toolbox. Beyond initial profiling, labor market interventions for the LTU generally require a step-by-step approach, starting from strengthening basic skills and coaching, followed by workplace-oriented training, vocational training and job search assistance. Austria, Belgium, Portugal, and the United Kingdom encourage employers to offer internships to the LTU by providing allowances for those registered with PES.

- $\quad$ Strong institutional cooperation. PES work with multiple stakeholders, including municipalities, youth and family services, other social services, and employers. Matching 
efficiency can be increased by strengthening cooperation on data and information exchange. One of the key recommendations by the European Commission is the establishment of a single point of contact, which is a reference point for the long-term unemployed and provide them with individualized, tailored guidance and simplified access to employment and support services (European Commission, 2016). In addition, cooperation can be in a form of outsourcing services to PES' partners that specialize in implementing measures in specific groups such as minorities and youth. For example, in France, PES work closely with the local agencies specialized for youth to train and integrate young people who lack qualifications into the labor market. Similarly, in Poland, one of the PES partners provides labor market services to young people under 25 years of age who dropped out of school.

- $\quad$ Post-employment support services. Once the long-term unemployed persons find jobs, it is important to ensure they stay employed. To this end, Bulgaria and Germany started a program aimed at sustaining integration of these individuals by providing them with followup support for a period of six months after placement. The support consists of a range of services, for instance, working on family and job compatibility issues, pre-employment training organized in cooperation with the employer, and prevention and resolution of risks in the initial phase of the employment). Based on a controlled experiment evaluation, retention rates significantly improved for the treatment group (European Commission, 2014). ${ }^{6}$

\section{SECTION V: CONCLUSIONS}

\section{This paper finds that LTU is associated with macroeconomic conditions and labor market characteristics, using annual data for 25 European countries over the period 2000-18.}

- Macroeconomic indicators: In all regressions, we find that LTU is persistent and counter-cyclical. As the economy expands in booms, the incidence of LTU tends to decline.

- Labor market characteristics: High LTU is also associated with elevated skill mismatches, high share of NEET, and declining labor market matching efficiency. We also find that the matching efficiency in Europe has declined relative to the pre-GFC level.

\section{ALMPs play an important role in alleviating LTU but the effectiveness varies} across programs. In our full multivariate analysis, we find that ALMPs have a significant impact on LTU, while unemployment benefits do not. Among different programs of ALMPs, we find that, in line with the existing literature, training programs and start-up incentives are effective tools to alleviate LTU.

\footnotetext{
${ }^{6}$ A simple regression analysis shows that higher matching efficiency is associated with lower registered unemployed persons in public employment services.
} 


\section{Measures to reduce the incidence of LTU include ensuring adequate spending on effective ALMPs, addressing skill mismatches, and promoting labor market matching efficiency.}

- Ensuring adequate spending on effective ALMPs: The average EU spending on ALMPs has declined compared to the pre-GFC levels. Ensuring adequate spending on ALMPs for several countries would help tackle the LTU. In addition, successful AMLPs typically combine different types of activation policies (such as training and wage subsidies).

- Addressing digital skill gaps: Technological advancement and digitalization lead to growing demand for digital skills. The COVID-19 pandemic and its aftermath further stress the importance of acquiring digital skills. Most EU countries continue to experience skill shortages in this aspect. To promote digital skill proficiency, countries should implement policies fostering digital skills including by investing in digital infrastructure, promoting digitalization of businesses, and integrating digital-skill development into school curriculum and training programs.

- Promoting labor market matching efficiency: One of the key instruments to improve the job matching efficiency, particularly for the disadvantaged and the long-term unemployed, is to strengthen the role of public employment services. This includes promoting policy coordination among key stakeholders, offering tailored programs for the LTU, and conducting post-monitoring program after the job placement. 


\section{REFERENCES}

Arpaia, A., Kiss, A., and Turrini, A., 2014, "Is Unemployment Structural or Cyclical? Main Features of Job Matching in the EU after the Crisis," No 91, IZA Policy Papers, Institute of Labor Economics (IZA).

Arellano, M. and Bond, S., 1991, "Some Tests of Specification for Panel Data: Monte Carlo Evidence and an Application to Employment Equations," Review of Economic Studies, 58, (2), 277-297.

Ball, L., Delong, B., and Summers L., 2014, "Fiscal policy and full employment." https://www.cbpp.org/research/full-employment/fiscal-policy-and-full-employment

Bassanini, A. and Duval, R., 2006, "Employment Patterns in OECD Countries: Reassessing the Role of Policies and Institutions," OECD Economics Department Working Papers 486, OECD Publishing.

Blanchard, O. and Summers, L., 1986, "Hysteresis and the European Unemployment Problem," NBER Macroeconomics Annual 1, 15-78.

Bova E., Jalles J., and Kolerus C., 2016, "Shifting the Beveridge Curve: What Affects Labor Market Matching?," IMF Working Paper, WP/16/93.

Caliendo, M. and Künn, S., 2011. "Start-up Subsidies for the Unemployed: Long-term Evidence and Effect Heterogeneity," Journal of Public Economics 95, 311-331.

Caliendo, M. and Schmidl, R., 2016, "Youth Unemployment and Active Labor Market Policies in Europe," IZA Journal of Labor Policy 5, 1.

Card, D., Kluve, J. and Weber, A., 2010, “Active Labor Market Policy Evaluations: a MetaAnalysis." The Economic Journal 120: F452-F477.

Card, D., Kluve, J. Weber, A. 2018, "What Works? A Meta Analysis of Recent Active Labor Market Program Evaluations." Journal of the European Economic Association, Volume 16 (3), 894-931.

Cedefop, 2016, "From Long-term Unemployment to a Matching Job: The Role of Vocational Training in Sustainable Return to Work," Luxembourg: Publications Office. Cedefop reference series; No 107.

Cedefop, 2018, "Insights into Skill Shortages and Skill Mismatch," Learning from Cedefop's European Skills and Jobs Survey, Luxembourg: Publications Office. Cedefop reference series; No 106 . 
Cedefop, 2018, "Skills Forecast: Trends and Challenges to 2030," Luxembourg: Publications Office. Cedefop reference series; No 108.

Duell, N., L. Thurau and T. Vetter, 2016, "Long-term Unemployment in the EU: Trends and Policies," Bertelsmann Stiftung, Gütersloh, https://www.bertelsmannstiftung.de/en/publications/publication/did/long-term-unemploymentin-the-eu/.

Escudero, V., 2018, "Are Active Labor Market Policies Effective in Activating and Integrating Low-skilled Individuals? An international comparison,” IZA Journal of Labor Policy 7(4).

Elhorst, J., 2003, "The Mystery of Regional Unemployment Differentials: Theoretical and Empirical Explanations,” Journal of Economic Surveys. 17. 709-748.

Estevao, M. and Tsounta E., 2011, "Has the Great Recession Raised the U.S. Structural Unemployment?” IMF Working Paper WP/11/105.

Eurofound, 2017, "Long-term Unemployed Youth: Characteristics and Policy Responses," Publications Office of the European Union, Luxembourg.

European Commission, 2013, "Cyclical and Structural Unemployment in the EU," Labor Market Developments in Europe 2013.

European Commission, 2014, "Approaches for Sustainable Integration of Long-Term Unemployed Toolkit," PES to PES Peer Review, Brussels.

European Commission, 2016, "Integration of the Long-term Unemployed," Summary Report on PES Network Conference.

European Commission, 2018, "Ad Hoc Module to the 2018 PES Capacity Questionnaire Survey Report," European Network of Public Employment Services.

European Commission, 2020, “European Economic Forecast Spring 2020,” Institutional Paper 125.

Forbes, 2020, "How to Prepare For a Post-Coronavirus Job Market," https://www.forbes.com/sites/bernardmarr/2020/05/18/how-to-prepare-for-a-post-coronavirusjob-market/\#15197a7a2f53

IMF, 2019, "Demographics Headwinds in Central and Eastern Europe," Washington D.C.

Heckman, J. and Pagés-Serra, C., "The Cost of Job Security Regulation: Evidence from Latin American Labor Markets," Economía Vol. 1 (1), 109-154. 
Kroft, K., Lange, F., Notowidigdo, M., and Katz, L., 2016, "Long-Term Unemployment and the Great Recession: The Role of Composition, Duration Dependence, and Nonparticipation," Journal of Labor Economics, University of Chicago Press, vol. 34(S1), S7-S54.

Machin, S. and Manning, A., 1999, "The Causes and Consequences of Long-term Unemployment in Europe," in Stephen Machin and Alan Manning (eds.), Handbook of Labor Economics, Vol 3, Part C, Elsevier.

Mitchell J., Nichols A., and Lindner S., 2013, "Consequences of Long-Term Unemployment," Urban Institute.

Mortensen, T. and Pissarides, A. 1994, "Job Creation and Job Destruction in the Theory of Unemployment.” Review of Economic Studies 61, 397-415.

OECD, 2004, “OECD Employment Outlook 2004.”

OECD, 2015, "Strengthening Public Employment Services," Paper Prepared for the G20 Employment Working Group, Istanbul, Turkey, 7-8 May 2015.

Petrongolo, B., and Pissarides, A., 2001, "Looking into the Black Box: A Survey of the Matching Function." Journal of Economic Literature, 39 (2), 390-431.

Pissarides, C., 2000, "Equilibrium Unemployment Theory, 2nd Edition," MIT Press Books, The MIT Press, edition 1, vol. 1, number 0262161877.

Robert, H. and Schulhofer-Wohl, S. 2018, "Measuring Job-Finding Rates and Matching Efficiency with Heterogeneous Job-Seekers," American Economic Journal: Macroeconomics, American Economic Association, vol. 10(1), 1-32, January.

Rodriguez-Planas, N., 2010, “Channels Through Which Public Employment Services and Small Business Assistance Programs Work," Oxford Bulletin of Economics Statistics (72), 458-485.

Shimer, R., 2012, "Reassessing the Ins and Outs of Unemployment," Review of Economic Dynamics. Elsevier for the Society for Economic Dynamics, vol. 15(2), 127-148, April.

The Bulgaria National Bank, 2019, "Labour Market Functioning and Matching Efficiency in Bulgaria over the Period 2004-2017: Qualification and Regional Aspects," BNB Discussion Paper, DP/114/2019.

UNESCO, 2018, "Building Tomorrow's Digital Skills-What Conclusions Can We Draw From International Comparative Indicators?,” Working Papers on Education Policy, Paris.

World Economic Forum, 2020, “The Future of Work is Here: 5 Ways to Reset Labor Markets After Coronavirus Recovery," Future of Work Forum, https://www.weforum.org/agenda/2020/05/the-future-of-work-is-here-5-ways-to-reset-labourmarkets-after-coronavirus-recovery/ 
APPENDIX I: DATA

Descriptive statistics

\begin{tabular}{lccccc}
\hline \multicolumn{1}{c}{ Variable } & $\begin{array}{c}\text { Number of } \\
\text { observations }\end{array}$ & Mean & $\begin{array}{c}\text { Standard } \\
\text { Deviation }\end{array}$ & Min & Max \\
\hline Incidence of LTU & 494 & 0.425 & 0.132 & 0.095 & 0.763 \\
GDP growth rate & 589 & 0.051 & 0.066 & -0.304 & 0.349 \\
Inflation rate & 583 & 0.026 & 0.033 & -0.017 & 0.457 \\
NEET & 557 & 14.649 & 5.455 & 4.100 & 32.500 \\
Skill mismatch & 520 & 14.518 & 8.084 & 0.772 & 43.126 \\
Matching efficiency & 280 & 0.680 & 0.528 & 0.159 & 4.615 \\
Tax wedge & 504 & 37.532 & 7.358 & 11.900 & 51.400 \\
Labor market policies & 446 & 0.371 & 0.289 & 0.033 & 2.129 \\
Training & 450 & 0.048 & 0.052 & 0.000 & 0.315 \\
Employment incentives & 448 & 0.036 & 0.040 & 0.000 & 0.219 \\
Supported employment and & & & & & \\
rehabilitation & 367 & 0.037 & 0.066 & 0.000 & 0.493 \\
Direct job creation & 382 & 0.024 & 0.039 & 0.000 & 0.328 \\
Start-up incentives & 405 & 0.004 & 0.006 & 0.000 & 0.035 \\
Unemployment benefits & 456 & 0.263 & 0.211 & 0.021 & 1.283 \\
\hline
\end{tabular}




\section{APPENDIX II: MEASURING LABOR MARKET MATCHING EFFICIENCY}

We estimate labor market matching efficiency based on the matching function approach. ${ }^{1}$ Matching efficiency is the productivity of the process for matching jobseekers to available jobs, such that, job finding is the output, whereas vacant jobs and active jobseekers are the inputs.

The process of matching job seekers with employers is assumed to be captured by the CobbDouglas matching function:

$$
m_{t}=\mu_{t} u_{t}^{\alpha} v_{t}^{1-\alpha}
$$

where $m_{t}$ is the number of new matches at time $t, \mu_{t}$ denotes matching efficiency, $u_{t}$ is the number of unemployed, $v_{t}$ is the number of vacancies, and $\alpha$ is the matching elasticity with respect to unemployed workers.

As the job finding rate $f_{t}$ is the ratio of new hires to the stock of unemployed workers, we have

$$
f_{t}=\mu_{t} \theta_{t}^{1-\alpha}
$$

where $\theta \equiv v / u$ is labor market tightness. For a given labor market tightness, matching efficiency determines the job finding rate; that is, the more efficient is the matching process, the higher rate at which job seekers can find new jobs at a given labor market tightness.

The labor force is normalized to one. The evolution of unemployed workers is given by

$$
u_{t+1}=s_{t}\left(1-u_{t}\right)+\left(1-f_{t}\right) u_{t},
$$

where $s_{t}$ is the separation rate. Thus, the number of unemployed workers at time $t+l$ is given by the number of unemployed workers who cannot find jobs at time $t$ plus employed workers who lose jobs at time $t$.

In the steady state, the equation (3) can be rewritten as

$$
\mu_{t}=s_{t}\left(1-u_{t}\right) /\left(u_{t} \theta_{t}^{1-\alpha}\right)
$$

Thus, we can compute the matching efficiency after estimating parameter $\alpha$ with the unemployment rate, separation rate, and labor market tightness.

\footnotetext{
${ }^{1}$ We estimate matching efficiency based on the standard search and matching model developed by Mortensen and Pissarides (1994), Veracierto (2011), and Shimer (2012). Other studies (Börsch-Supan, 1991; Wall and Zoega, 2002; Valetta, 2005; Bonthuis et al., 2013) determine a degree of matching efficiency through a shift in the Beveridge curve, which dictates a negative relationship between vacancies to the number of unemployed. In particularly, an inward shift in the Beveridge curve depicts a higher degree of job matching efficiency because given numbers of vacancies constant, number of unemployed is lower as the unemployed is finding the jobs and fill in vacancies faster, and vice versa.
} 
The elasticity of matching function with respect to unemployment can be estimated from

\section{Data and results}

$$
\ln f_{t}=\ln \mu_{t}+(1-\alpha) \ln \theta_{t}+\varepsilon_{t}
$$

We obtain quarterly data of the unemployment rate, unemployment, and job vacancy rate for 23 European countries from Eurostat. ${ }^{2}$ The choice of countries depends mainly on data availability. The sample period varies across countries and spans the longest timeframe for which data is available. As for job finding and separation rates, following Elsby et al. (2009) and Shimer (2012) we construct these series by using data on the short-term unemployment and total unemployment. ${ }^{3}$ The short-term unemployment is measured by workers who have been unemployed for less than three months.

Table A1 reports the sample averages of job finding and separation rates and estimates matching elasticities with respect to unemployment. The job finding rates range from 11.9 percent in Greece to 57.5 percent in Finland. The separation rates range from 1.4 percent in Slovakia to 5.2 percent in Spain. As for the matching elasticity with respect to unemployment, most estimated values lie in the plausible range of $0.5-0.7$, which is reported by Petrongolo and Pissarides (2001).

\footnotetext{
${ }^{2}$ Sample countries are Belgium, Bulgaria, Cyprus, Czech Republic, Denmark, Germany, Spain, Estonia, Finland, United Kingdom, Greece, Croatia, Hungary, Ireland, Latvia, Lithuania, Norway, Poland, Portugal, Romania, Slovakia, Slovenia, Spain, and Sweden.

${ }^{3}$ In this paper, the job finding rate is defined as the rate of transition from unemployment to employment. Similarly, the separation rate is defined as the rate of transition from employment to unemployment.
} 
Table A1. Worker flow rates and matching elasticities

\begin{tabular}{|llccc|}
\hline Country & Sample period & Job finding rate & Separation rate & Elasticity of matching function alfa \\
\hline Belgium & 2010Q1-2019Q1 & 29.9 & 2.2 & 0.87 \\
Bulgaria & 2005Q1-2019Q1 & 17.4 & 1.5 & 0.59 \\
Cyprus & 2005Q1-2019Q1 & 34.0 & 2.8 & 0.75 \\
Czech Republic & 2008Q1-2019Q1 & 28.3 & 1.4 & 0.82 \\
Denmark & 2010Q1-2019Q1 & 51.2 & 3.3 & 0.76 \\
Germany & 2006Q1-2019Q1 & 30.6 & 1.6 & 0.79 \\
Spain & 2001Q1-2019Q1 & 35.4 & 5.2 & 0.30 \\
Estonia & 2008Q3-2019Q1 & 38.8 & 3.4 & 0.52 \\
Finland & 2003Q1-2019Q1 & 57.5 & 5.1 & 0.80 \\
United Kingdom & 2001Q2-2019Q1 & 48.0 & 2.9 & 0.54 \\
Greece & 2009Q1-2019Q1 & 11.9 & 2.5 & 0.73 \\
Croatia & 2012Q1-2019Q1 & 19.4 & 2.4 & 0.32 \\
Hungary & 2006Q1-2019Q1 & 24.0 & 1.8 & 0.61 \\
Ireland & 2008Q1-2019Q2 & 24.9 & 2.4 & 0.59 \\
Latvia & 2005Q1-2019Q1 & 27.2 & 3.1 & 0.59 \\
Lithuania & 2004Q1-2019Q1 & 29.3 & 2.8 & 0.67 \\
Norway & 2009Q1-2019Q1 & 51.6 & 2.0 & 0.72 \\
Poland & 2007Q1-2019Q1 & 30.3 & 2.3 & 0.72 \\
Portugal & 2001Q1-2019Q1 & 23.0 & 2.5 & 0.64 \\
Romania & 2009Q4-2019Q1 & 27.0 & 1.8 & 0.64 \\
Slovakia & 2004Q1-2019Q1 & 12.4 & 1.4 & 0.60 \\
Slovenia & 2008Q1-2019Q1 & 22.9 & 1.8 & 0.57 \\
Sweden & 2009Q1-2019Q1 & 51.8 & 4.3 & \\
\hline & & & & \\
\hline
\end{tabular}


Figure A1: Evolution of Matching Efficiency in Europe

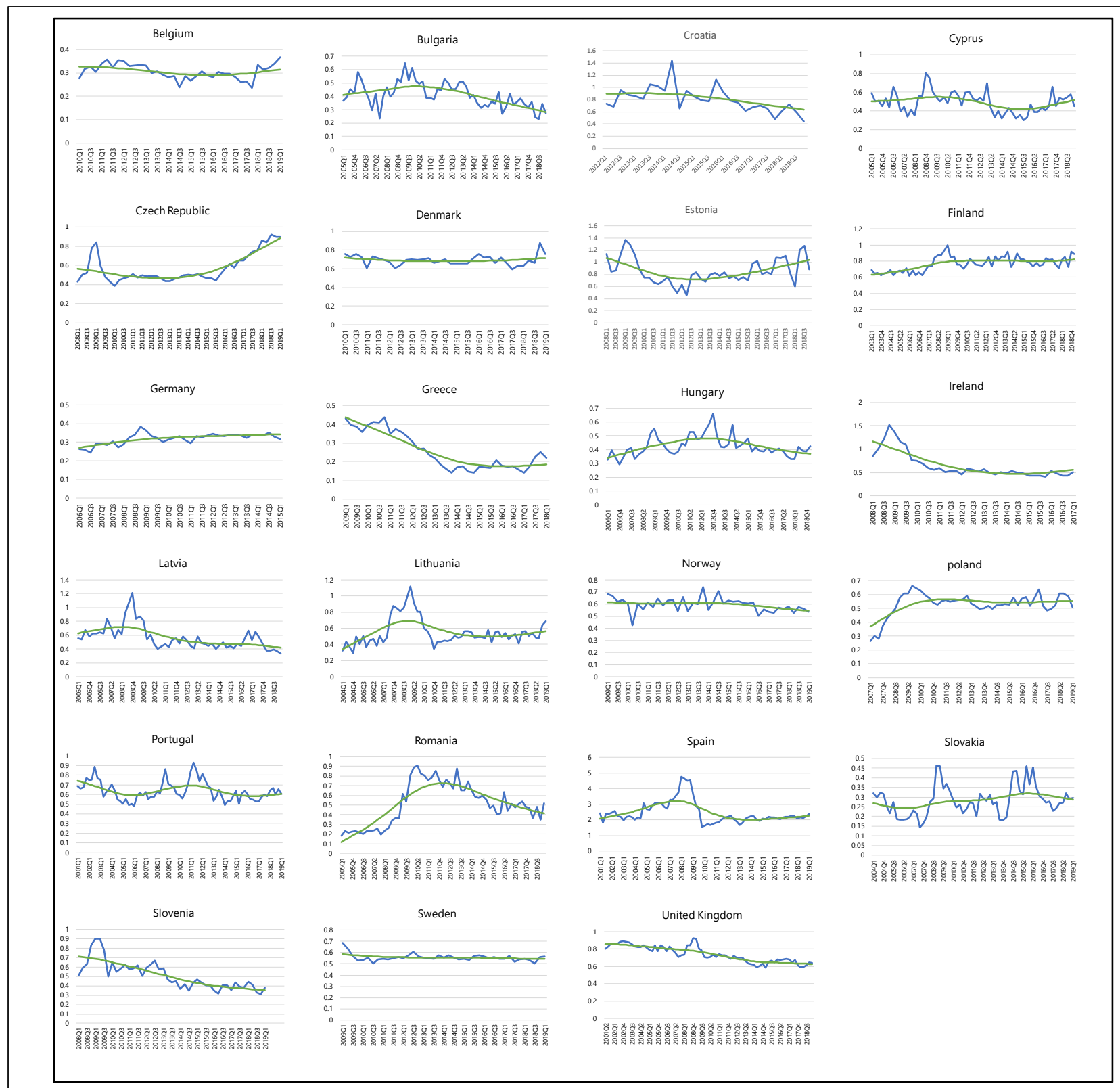

For Spain, the high job matching efficiency is likely to be driven by high separation rate. This finding is in line with Arpaia et al. (2014) and Hobijn and Shin (2007). 